\title{
Smart Manufacturing Concept in Shipbuilding Process with Related Optimization Issues and Strategies
}

\author{
Alfonsus Julanto Endharta ${ }^{1, a,}$, Defi Norita ${ }^{2,3, b}$, Ivan Kristianto Singgih',4,c,*, A. Aris Wacana \\ Putra $^{5, \mathrm{~d}}$, Moses Laksono Singgih ${ }^{4, \mathrm{e}}$, Putri Dyah Setyorini ${ }^{6, \mathrm{f}}$ and A. A. B. \\ Dinariyana $^{6, g}$ \\ ${ }^{1}$ Department of Industrial and Management Engineering, Pohang University of Science and \\ Technology, Pohang, South Korea \\ ${ }^{2}$ Department of Industrial Engineering, Mercubuana University, Jakarta, Indonesia \\ ${ }^{3}$ Department of Agroindustrial Technology, Bogor Agricultural University, Bogor, Indonesia \\ ${ }^{4}$ Department of Industrial Engineering, Sepuluh Nopember Institute of Technology, Surabaya, \\ Indonesia \\ ${ }^{5}$ Naval Ship Division, PT. PAL Indonesia, Surabaya, Indonesia \\ ${ }^{6}$ Department of Marine Engineering, Sepuluh Nopember Institute of Technology \\ Surabaya, Indonesia \\ a.endharta@postech.ac.kr,b.defi.norita@gmail.com, c.ivanksinggih@postech.ac.kr, d. \\ ariswp@gmail.com,e.moseslsinggih@ie.its.ac.id,f.putridyahs@gmail.com,g.kojex@its.ac.id \\ *ivanksinggih@postech.ac.kr
}

Keywords: $\quad$ Big Data, Real-Time, Optimization, Shipbuilding, Smart Manufacturing.

Abstract: Smart manufacturing is mainly dealing with the collection of real time data using sensors and the data utilization to improve a system. In this study, important characteristics of smart manufacturing, which must be considered in shipbuilding are presented. Shipbuilding process itself consists of various complex operations, starting from the ship design until the delivery to customers. However, this paper only focuses on the production and control activities for the shipbuilding product. Some required smart technologies, such as augmented reality, big data, and smart sensors, are listed. Various optimization problems in shipbuilding process that utilizes the collected data are defined. In addition, strategies related with smart manufacturing concept, which are required to solve problems are addressed. Relations between the optimization problems and strategies are described, and expected increase in the company's productivity after the implementation of the smart manufacturing concept is discussed. In addition, suggestions for future researches are proposed.

\section{Introduction}

Smart manufacturing is the fourth revolution in the manufacturing industry that supports effective and accurate real time decision-making by utilizing various ICT technologies [1]. Smart manufacturing concept is a basic concept of some programs, such as Industry 4.0 in Germany, NIST 
or Smart Manufacturing Leadership Coalition (SMLC) in U.S., research plans proposed by Ministry of Trade, Industry, and Energy (MOTIE) or Ministry of Science, ICT, and Future Planning (MSIP) in Korea, and Made in China 2025. The rising number of participating parties in the programs, such as 25 companies, 7 universities, and 1 government research institute in SMLC, shows that the smart manufacturing is a highly valued concept. The smart concept itself is being studied in various fields, such as logistics [2], product development, hospital services, and city management [3].

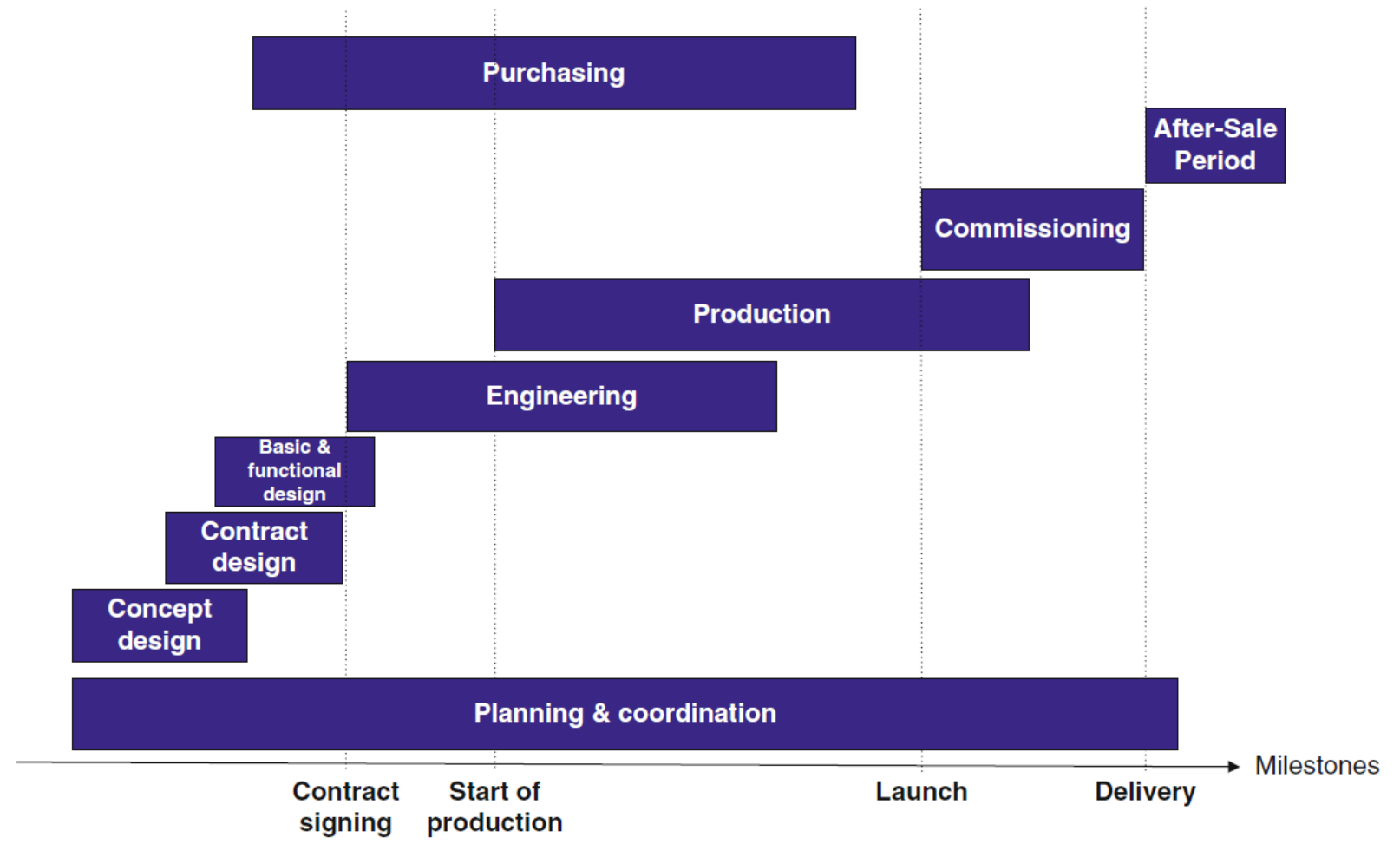

Figure 1: Main activities in the shipbuilding industry [4].

In smart manufacturing, it is expected to satisfy the agile and dynamic requirements during the production process [3]. The requirements may arise from the customer demand and some sudden changes in the production floor. Dealing with these requirements becomes possible due to the development of Internet of Things (IoT) technologies. The implementation of IoT improves customer satisfaction, supports smooth flow of materials, and increases the production output.

Smart manufacturing concept has been implemented in shipbuilding industry. The sequence of activities in the shipbuilding industry is mainly started from the design process, material purchasing, production, and ended with after-sales services, as presented in Figure 1. In this study, implementations of smart manufacturing technologies within several activities in previous researches are listed. In addition, further analysis of appropriate optimization approaches and possible research topics in the production process are discussed.

The paper is written as follows: in the next section, main characteristics of smart manufacturing and possible implementations of smart manufacturing concepts in the shipbuilding industry are listed. Section 3 discusses about optimization issues in shipbuilding industry and required strategies to solve the problems. Finally, Section 4 concludes this study. 


\section{Smart Manufacturing in Shipbuilding Industry}

Smart manufacturing focuses on improving following major manufacturing factors, such as productivity, quality, delivery, and flexibility [1]. It may be seen that smart manufacturing aims to improve the current system performance and deal with occurred rapid changes that affect the system. Improving the current system may be possible after gathering data related with settings used in the production floor, such as machine speed, generated schedule, and its resulted performance.

Rapid changes that occur in the industry may be fast customer demand changes or sudden unexpected disturbances in the shop floor. As the IoT and smart manufacturing concept develop, customers' expectations of product quality and their preferred product customization can affect production decision more than the manufacturers and retailers behaviours [3]. The unexpected situations which may occur in the production system are machine breakdowns, deviations in processing times, arrival of new products, and changed priority of tasks. Some reasons above are unavoidable, e.g. machine breakdowns, while the others can be prevented by designing appropriate look-ahead planning process, preventive maintenance scheduling, and other strategies.

Main technologies used in smart manufacturing are Cyber Physical System (CPS), Internet of Things (IoT), cloud computing, big data, 3D printing, sensors, and Radio Frequency Identification (RFID). Some detailed explanations are provided in [1,3]. The development and implementations of these technologies are related with each other, e.g. CPS is based on heterogeneous data and knowledge integration [3], while the data are collected using sensors and stored using big data and cloud computing techniques.

Big data researches study about collection, storage, analysis, and usage of data [5]. Three main dimensions of big data are volume, variety (formats), and velocity (time interval between data generation). Efficient analytical methods are required to process the data in order to solve real-time problems in smart manufacturing concept. Ref. [3] stated that big data is one of key technologies of smart manufacturing because big data supported information sharing to connect networks of human and robots in CPS. Big data has been used by Raytheon Corp to enable smart factory with a high capacity of managing information from various sources, such as sensors, equipment, Internet transactions, simulations, and digital records of the company [6]. More detailed information about big data concept and implementations are provided in [7-8].

Smart manufacturing concepts in shipbuilding industries are discussed in [9-11]. Ref. [9] stated that virtual reality (VR) system was utilized to help shipbuilding designers evaluating ship designs using a 3D view. The proposed system enabled the designers to assess ergonomic aspects of the design, view the object attributes, add notes, and detect design inconsistencies with the whole ship production process. It led to effective analysis for identifying possible errors in all stages of the design and reducing the cost and time for rework in the production phase due to inappropriate designs. Ref. [10] introduced an automated closed-loop approach for an entire ship design process. The proposed design process was supported with a fully digitalized and connected network, which enabled self-gathering and analysis of important features in the design. The generated 3D model was shared on the cloud and could be updated by the ship owner and engineers. The approach fostered a high volume of communication between stakeholders and allowed the manufacturer to prevent reworks, which might occur during the actual production process. Ref. [11] explained how augmented reality technology was used to provide good imagination about the metal shape and required work procedure during the metal forming process. The proposed technology could be used to confirm the quality of the formed metal, while replacing the traditional method, which required the workers to match the processed metals with given templates manually. 
General researches about smart manufacturing that may be implemented in shipbuilding industry are conducted by [1,12]. Ref. [1] mentioned that a worker-oriented smart helmet development was suggested by MSIT, Korea, which enabled data acquisition by the workers. This technology may be utilized to provide data required by the workers during the production process, which currently may be stored in piece of papers of computer files. Ref. [12] presented a job shop scheduling problem, in which RFID is used to record real-time manufacturing data. In this system, a RFID tag was attached on each container that is used to contain raw materials. When the container with the tag entered or leaved the machining area, the time was recorded and uploaded into a database. The collected data were used as the basis for generating schedules in a real-time job shop environment.

\section{Optimization Issues and Strategies}

In this section, various optimization issues related with the data collection and utilization in shipbuilding manufacturing process are discussed, such as:

1. Spatial scheduling of ship assembly blocks [13-15]. In this spatial scheduling problem, the position of blocks in workplaces must be determined, while considering various requirements, such as due date for each block, size of each block, and adjacent placement for some symmetric blocks. The objectives may be minimizing the make span and imbalanced workloads over workplaces.

2. Assembly line balancing problem [16]. In this problem, some hull blocks can be assembled at the same time. The objectives are minimizing cycle time and deviation of workloads between stations.

3. Block transportation $[17,18]$. After an assembly process, assembled blocks must be transported using cranes from the production yard. While performing the transportation, the waiting times of assembled blocks must be minimized. Ref. [17] stated the importance of considering inter-crane interferences. Decisions to be made are sequence of jobs and assignment of jobs to cranes. Ref. [18] explained how transportation data can be recorded and analyzed in order to evaluate current transportation practice and perform necessary improvements.

4. Transporter scheduling and routing [19-20]. The transporters are used to move ship blocks within a given time, while considering sequence-dependent setup times, precedence constraints, and workload balance between transporters. In addition, multiple transporters may be necessary to transport large blocks.

5. Skid scheduling [21]. A skid system is used to combine subassembly blocks into a ship. Different with the general dock at which only one ship can be built, using the skid system, more than one ships can be constructed simultaneously.

6. Man-hours estimation and optimization [22-23]. In [22], after being estimated, the man-hour requirements are used as input for a welding scheduling problem. Given each block's ship type, shape, size, and the block's assembly shop, the required man-hour is estimated. Decisions to be made are two-dimensional location and time required by each ship. The objectives are maximizing the number of built ships on the skid and minimizing early or delayed ship launching. In the man-hour optimization problem [23], man-hours are allocated to minimize the total man-hour time required for parallel tasks.

7. Bottleneck detection and solving [24-26]. Bottlenecks can be detected by identifying machines with highest value of system production rate with respect to its working (non-idle) time, observing machines that has previous machines with higher blockage than starvation levels and successive machines with lower blockage than starvation levels, and performing simulation with some replications in order to assess which machine has the largest total operational time. Methods for solving the bottlenecks are increasing utilization rate and minimizing setup time of 
the bottleneck machine, reducing processing times in bottleneck machine and increase the time in non-bottleneck machines, and implementing drum-buffer-rope (DBR) strategy. In DBR, nonbottleneck machines must be used to enhance the performance of bottleneck machine. Thus, nonbottleneck machines must receive jobs just in time and in right quantities in order to increase the utilization of the bottleneck machine.

In order to deal with these optimization issues, some strategies are proposed, which are highly related with rapid data acquisition process. The optimization strategies are data collection, realtime, robust, rescheduling and online, and multi-discipline optimizations, which are shown in Figure 2.

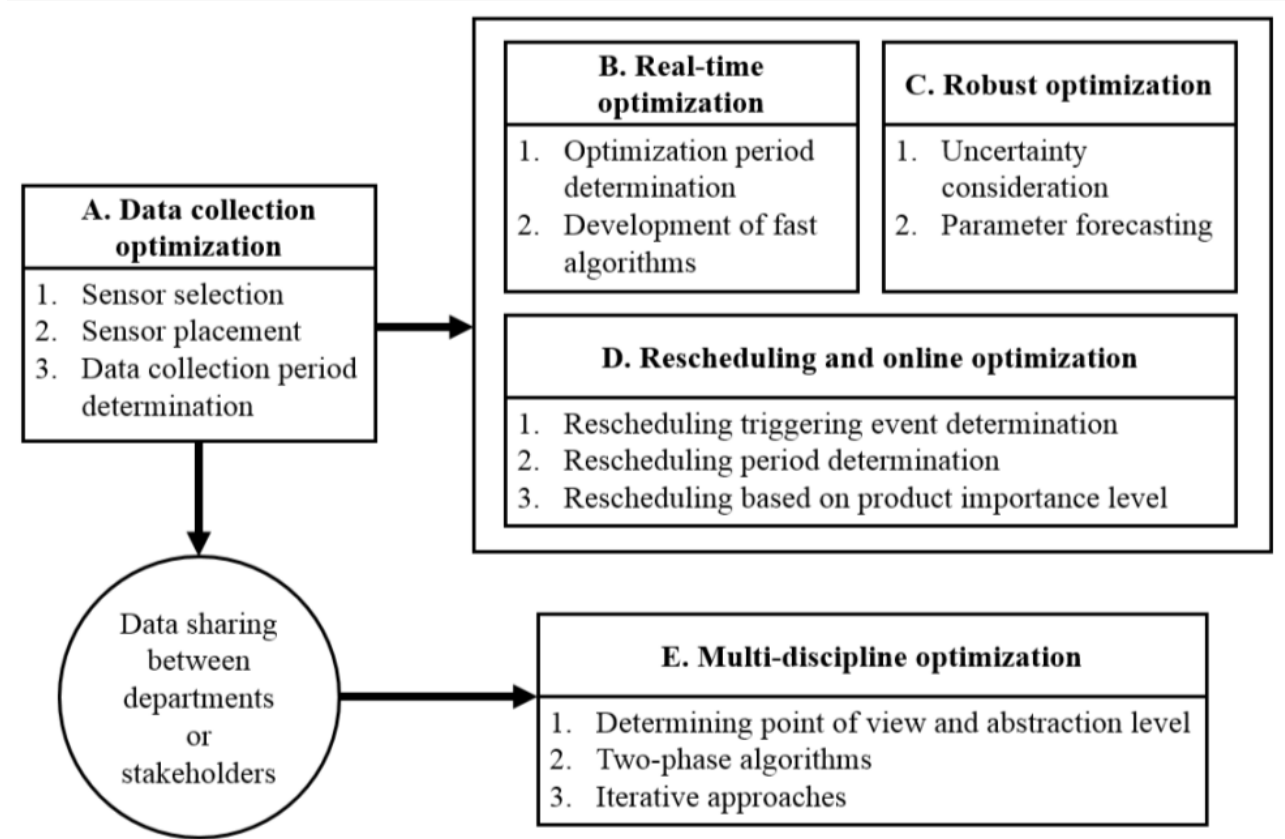

Figure 2: Considered optimization strategies related with smart manufacturing concept.

\subsection{Data Collection Optimization}

Data to be collected are related with the parameters or triggering events stated for each optimization problem above. Data collection must be collected continuously in order to obtain required real-time information for the planning process and identify anomaly in the production system.

Real operational data in shipbuilding process are continuously collected using sensors. Appropriate number of sensors and their placements may be important to determine the accuracy of the obtained data, e.g. in order to measure the flow time of a product in the production line, RFID tag sensors must be placed exactly at the beginning and the end of the line. Sensor selection and placement can be optimized in order to obtain greater, in terms of amount, and better output while minimizing the required installation costs.

Considering that the size of collected data may be very large, a huge storage space may be required. In order to record the data and utilize the storage space effectively, the data selection and collection period must be optimized. Even the data can be stored into the cloud, the time required to record, store, and retrieve the data during the optimization process need to be taken into account. Some data collection requires a huge effort but only has a small influence to the objective. In this case, the data collection may not be performed. The appropriate data collection period can be determined by identifying when important events occur in the historical data. The events can be 
assumed to occur at deterministic times or within a certain time interval, while considering their stochastic occurrences.

\subsection{Real-time Optimization}

Real-time optimization is an optimization approach that is attempted to improve system performance in real-time. Ref. [27] explained that the implementation of smart manufacturing concept enabled real-time scheduling in the manufacturing process. One of the implemented smart manufacturing concept is RFID [28].

In order to perform real-time optimization, it is necessary to produce good solutions in a very short time. Therefore, good and fast algorithms need to be developed [29-30]. Fast computation ability of the algorithms enable the system to comply with increased customer's demand variety and support the mass production of customized products.

\subsection{Robust Optimization}

Robust optimization ensures system ability to perform well under dynamic and uncertain environments [31-32]. In robust optimization, uncertainties are considered during the planning phase by considering various possible parameter values in the model [32]. The obtained solution may not be the best, but it can still have a good performance even many disturbances occur in the production floor. In the extreme case, the most pessimistic (worst) parameter values are used in order to assure good performance in that most unexpected situation, e.g. the largest processing times in a machine and full buffer spaces.

The parameter values used in the model can be forecasted based on the data, which are continuously being extracted using the sensors and stored into the database, e.g. using regression analysis [33]. By performing the forecasting, the generated schedules can be appropriate with the latest status of the system. In other words, the operations can be flexibly planned based on the current situation.

\subsection{Rescheduling and Online Optimization}

Rescheduling is defined in [34] as a revision of an existing schedule in response to changes or disruptions. Rescheduling can be performed every time an event triggers it, meanwhile online optimization has a broader scope because it is conducted not only when triggered by a certain event, but also on a regular rescheduling period. In the event-triggered based rescheduling, the system automatically provides feedbacks related with inappropriate or new behaviors in the model, e.g. the waiting time at a machine exceeds a certain level, the number of produced items per hour becomes less than a certain value, the total processing time exceeds a certain ideal standard obtained based on previously generated schedules [34], arrival of new jobs [35], re-arrival of rework jobs [36], cancellation of jobs [37-38], delay of job completion that is more than a threshold [39] and many more. The thresholds can also be determined using an optimization model in order to obtain appropriate values.

Online scheduling approach is implemented by using a rolling horizon approach [34]. In this approach, the time interval between schedule generations is shorter than the planning horizon. Every time a schedule is generated, some parts of the previously generated schedule are modified, while some new parts of the schedule are added. In a more flexible way, the time interval between planning horizons itself can be modified based on the workload of the system. When there is more workload, the scheduling is performed more often. 
Before performing the rescheduling or online optimization, an intended change in weight parameter for each task can be performed in order to control the task importance during the optimization process, e.g. by increasing the weight for products which are processed late in the current schedule. The weight parameters can also be modified if a new task enters the system.

\subsection{Multi-Discipline Optimization}

A huge amount of collected data provides an opportunity to have better understanding about each part of the system, and allows us to optimize a subsystem or even the whole system. Given the development of good processors, the computational time required to handle this large amount of data may not be questioned further. On the other hand, it is necessary to design an integrated approach to perform the cross-functional planning between departments in the organization, e.g. between the procurement, manufacturing, and sales departments. This integrated approach is defined as an approach, in which coupled decisions of several supply chain functions, are considered [40].

Optimization problem in each department can have some trade-off relationships, e.g. producing many items may not be good because it increases the inventory level, and meanwhile it is necessary to assure that all products are always available to be sold. However, optimizing each problem separately may prevent us to obtain a good solution for the whole system. In order to perform the cross-functional optimization, it is necessary to define the problems clearly. The optimization can be performed in two-phase or iterative approaches. In the two-phase method, it may be sufficient to consider only important factors of the subsystems. The obtained values of decision variables in the first phase may further be used to optimize each subsystem using more detailed models in the second phase. In the iterative approach, the results obtained in the second phase can be used as input to re-optimize the problem in the first phase.

The optimization can also be performed within a supply chain by allowing data share between all parties. This kind of optimization may lead to a more efficient planning and strengthen the competitiveness of the parties in the supply chain. However, each party may not accept this data sharing in order to preserve its important business strategies, market share, and profit. In order to perform coordination, while preserving important data, limited data may be shared between parties [41]. Thus, the integrated approach must be mainly be implemented within each party, in which higher manageability degree exists, and may be extended to other parties, while emphasizing on the profit that can be obtained after the data sharing and coordination. Meanwhile, the approach seems to be applicable well within supply chain parties with strong agreement or when a party is a subcompany of another leading party.

Several implementations of the multi-discipline or multi-parties optimization in shipbuilding industry are:

1. Man-hour overlapping optimization between design and construction departments [42]. Feasibility of the designed man-hour plan is assessed and impact of design rework on construction man-hours is investigated.

2. Project management considering engineering, purchasing, and production departments [43]. Resources to be considered are one of more among time, space capacity, and cost.

3. Resource sharing [44]. Sharing the data allows the parties to share resources with each other in order to assure in-time delivery of the final products.

4. Addition and removal of parties from shipbuilding industry cluster [45]. 


\section{Conclusions}

In this study, important characteristics of smart manufacturing concept, which are required in shipbuilding industry, are listed. Optimization problems in the shipbuilding industry are addressed and appropriate strategies to solve the problems are discussed in detail. Future researches may investigate more detailed implementations of the presented optimization strategies.

\section{References}

[1] H.S. Kang, J.Y. Lee, S. Choi, H. Kim, J.H. Park, J.Y. Son, B.H. Kim, S.D. Noh, "Smart manufacturing: past research, present findings, and future directions," International Journal of Precision Engineering and Manufacturing-Green Technology, vol. 3, no. 1, pp. 111-128, 2016.

[2] L. Barreto, A. Amaral, and T. Pereira, "Industry 4.0 implications in logistics: an overview," Procedia Manufacturing, vol. 13, pp. 1245-1252, June 2017 [Manufacturing Engineering Society International Conference 2017 Spain, 2017].

[3] Y. Lu, "Industry 4:0: A survey on technologies, applications and open research issues," Journal of Industrial Information Integration, vol. 6, pp. 1-10, 2017.

[4] S. Haji-kazemi, E. Arica, M. Semini, E. Alfnes, and B. Andersen, "Detecting early warning signs of delays in shipbuilding projects," In S. Umeda et al., "Advances in production management systems: Innovative production management towards sustainable growth, " IFIP WG 5.7 International Conference APMS Japan, p. 215-222, 2015.

[5] R.F. Babiceanu and R. Seker, "Big data and virtualization for manufacturing cyber-physical systems: A survey of the current stateus and future outlook," Computers in Industry, vol. 81, pp. 128-137, 2016.

[6] A. Noor, "Putting big data to work," ASME Mechanical Engineering, vol. 135(10), pp. 32-37, 2013.

[7] B. Tjahjono, C. Esplugues, E. Ares, and G. Pelaez, "What does Industry 4.0 mean to supply chain," Procedia Manufacturing, vol. 13, pp. 1175-1182, 2017.

[8] Y. Cheng, K. Chen, H. Sun, Y. Zhang, and F. Tao, "Data and knowledge mining with big data towards smart production, ” Journal of Industrial Information Integration, vol. 9, pp. 1-13, 2018.

[9] R.P. Fernandez and V. Alonso, "Virtual reality in a shipbuilding environment," Advances in Engineering Software, vol. 81, pp. 30-40, 2014.

[10] J.H. Ang, C. Goh, and Y. Key, "Smart design for ships in a smart product through-life and Industry 4.0 environment," IEEE World Congress on Computational Intelligence, pp. 5301-5308, 2015.

[11] K. Matsuo, U. Rothenburg, and R. Stark, "Application of AR tehcnologies to sheet metal forming in shipbuilding," Smart Product Engineering, LNPE, pp. 937-945, 2013.

[12] C. Cuihua, L. Sheng, L. Pengfei, and L. Wang, "Active shop scheduling of production process based on RFID technology,” MATEC Web of Conferences, pp. 42, 2016.

[13] K. Park, K. Lee, S. Park, and S. Kim, "Modeling and solving the spatial block scheduling problem in a shipbuilding company," Computers \& Industrial Engineering, vol. 30, pp. 357-364, 1996.

[14] J. Zheng, Z. Jiang, Q. Chen, and Q. Liu, "Spatial scheduling algorithm minimising makespan at block assembly shop in shipbuilding," International Journal of Production Research, vol. 49(8), pp. 2351-2371, 2011.

[15] B. Kwon and G.M. Lee, "Spatial scheduling for large assembly blocks in shipbuilding," Computers \& Industrial Engineering, vol. 89, pp. 203-212, 2015.

[16] Z. Yuguang, A. Bo, and Z. Yong, "A PSO algorithm for multi-objective hull assembly line balancing using the stratified optimization strategy, ” Computers \& Industrial Engineering, vol. 98, pp. 53-62, 2016.

[17] C. Wen, S.D. Ekşioglu, A. Greenwood, and S. Zhang, "Mining transportation logs for understanding the afterassembly block manufacturing process in the shipbuilding industry," Expert Systems with Applications, vol. 124, pp. 40-50, 2010.

[18] S-K. Lee, B. Kim, M. Huh, X. Cho, S. Park, and D. Lee, "Mining transportation logs for understanding the afterassembly block manufacturing process in the shipbuilding industry, " Expert Systems with Applications, vol. 40, pp. 83-95, 2013.

[19] C. Park and J. Seo, “A GRASP approach to transporter scheduling and routing at a shipyard,” Computers \& Industrial Engineering, vol. 63, pp. 390-399, 2012.

[20] Z.-H. Hu and C. Wei, "Synchronizing vehicles for multi-vehicle and one-cargo transportation," Computers \& Industrial Engineering, vol. 119, pp. 36-49, 2018.

[21] H. Yoon, S. Koh, and R. Logendran, "Skid scheduling algorithm for a shipbuilding company," International Journal of Production Research, vol. 50(10), pp. 2774-2784, 2012. 
[22] J.K. Lee, K.J. Lee, H.K. Park, J.S. Hong, and J.S. Lee, "Developing scheduling systems for Daewoo Shipbuilding: DAS project," European Journal of Operational Research, vol. 97, pp. 380-395, 1997.

[23] Y. Mei, Z. Zeng, D. Feng, and Y. Tu, "A method for man hour optimisation and workforce allocation problem with discrete and non-numerical constraints in large-scale one-of-a-kind production," International Journal of Production Research, vol. 54(3), pp. 864-877, 2016.

[24] M. Gupta, H.-J. Ko, and H. Min, "TOC-based performance measures and five focusing steps in a job-shop manufacturing environment," International Journal of Production Research, vol. 40(4), pp. 907-930, 2002.

[25] M. Thürer, M. Stevenson, C. Silva, and T. Qu, "Drum-buffer-rope and workload control in high-variety flow and job shops with bottlenecks: An assessment by simulation," International Journal of Production Economics, vol. 188, pp. 116-127, 2017.

[26] L. Li, "A systematic-theoretic analysis of data-driven throughput bottleneck detection of production systems," Journal of Manufacturing Systems, vol. 47, pp. 43-52, 2018.

[27] Y. Zhang, S. Liu, Y. Liu, H. Yang, M. Li, D. Huisingh, and L. Wang, "The 'Internet of Things' enabled real-time scheduling for remanufacturing of automobile engines," Journal of Cleaner Production, vol.185, pp. 562-575, 2018.

[28] H. Luo, J. Fang, and G.Q. Huang, "Real-time scheduling for hybrid flowshop in ubiquitous manufacturing environment," Computers \& Industrial Engineering, vol. 84, pp. 12-23, 2015.

[29] M. Ham, Y.H. Lee, and S.H. Kim, "Real-time scheduling of multi-stage flexible job shop floor," International Journal of Production Research, vol. 49(12), pp. 3715-3730, 2011.

[30] P.M. Khodke and A.S. Bhongade, "Real-time scheduling in manufacturing system with machining and assembly operations: A state of art," International Journal of Production Research, vol. 51(16), pp. 4966-4978, 2013.

[31] A. Che, J. Feng, H. Chen, and C. Chu, "Robust optimization for the cyclic hoist scheduling problem," European Journal of Operational Research, vol. 240, pp. 627-636, 2015.

[32] J.J. Palacios, I. Gonzáles-Rodríguez, C.R. Vela, and J. Puente, "Robust multiobjective optimisation for fuzzy job shop problems," Applied Soft Computing, vol. 56, pp. 604-616, 2017.

[33] S. Nagahara and Y. Nonaka, "Product-specific process time estimation from incomplete point of production data for mass customization," Procedia CIRP, vol. 67, pp. 558-562, 2018.

[34] D. Gupta, C.T. Maravelias, and J.M. Wassick, "From rescheduling to online scheduling," Chemical Engineering Research and Design, vol. 116, pp. 83-97, 2016.

[35] Y. Guo, M. Huang, Q. Wang, and V.J. Leon, "Single-machine rework rescheduling to minimize maximum waitingtimes with fixed sequence of jobs and ready times," Computers \& Industrial Engineering, vol. 91, pp. 262-273, 2016.

[36] L. Liu and H. Zhou, "On the identical parallel-machine rescheduling with job rework disruption," Computers \& Industrial Engineering, vol. 66, pp. 186-198, 2013.

[37] C. Chen, T. Gärling, and R. Kitamura, “Activity rescheduling: reasoned or habitual?,” Transportation Research Part F, vol. 7, pp. 351-371, 2004.

[38] X. Li, Z. Peng, B. Du, J. Guo, W. Xu, and K. Zhuang, "Hybrid artificial bee colony algorithm with a rescheduling strategy for solving flexible job shop scheduling problems," Computers \& Industrial Engineering, vol. 113, pp. 10-26, 2017.

[39] Z. Liu, L. Lu, and X. Qi, "Cost allocation in rescheduling with machine unavailable period," European Journal of Operational Research, vol. 266, pp. 16-28, 2018.

[40] M. Darvish and L.C. Coelho, "Sequential versus integrated optimization: Production, location, inventory control, and distribution," European Journal of Operational Research, vol. 268, pp. 203-214, 2018.

[41] K. Schopka and H. Kopfer, "Pre-selection strategies for the dynamic collaborative transportation planning problems," in Operations Research Proceedings 2014: Selected papers of the annual international conference of the German operations research society, M. Lübbecke, A. Koster, P. Letmathe, R. Madlener, B. Reis, and G. Walther, Eds. Aachen: Springer, 2014, pp. 523-529.

[42] H. Moyst, Optimizing the Integration of Ship Design with Construction: A Linear Programming Approach. Master Thesis. Ottawa, Canada: Dalhousie University, 2001.

[43] R. van Dijk, N. Gademann, J.M.J. Schutten, and G. Schouten, "Multi-project planning in shipbuilding," 2002 [Proceedings of the 11th International Conference on Computer Applications in Shipbuilding Sweden, p. 429, 2002].

[44] A. Kusiak, "Smart manufacturing," International Journal of Production Research, vol. 56, pp. 508-517, 2018.

[45] S. Yil, W. Fa-yin, and A. Xiao-li, "Coupling mechanism and coupling degree measurement model of shipbuilding industry cluster," Polish Maritime Research, vol. 23, pp. 78-85, 2016. 